\title{
Function of Anti-CoV Structure Using INH [1-6]- Tyr160- Met161-His162 Complex
}

\author{
Fatemeh Mollaamin 1,* (D) \\ 1 Department of Chemical Engineering, Central Tehran Branch, Islamic Azad University, Tehran, Iran \\ * Correspondence: smollaamin@gmail.com (F.M.);
}

Scopus Author ID 35848813100

Received: 4.02.2021; Revised: 6.03.2021; Accepted: 10.03.2021; Published: 22.03.2021

\begin{abstract}
Coronaviruses (CoVs), positive-stranded RNA viruses, can infect humans and multiple species of animals, cause enteric, respiratory, and central nervous system diseases in many species, and are attractive targets for anti-CoV drug design through a pivotal role in viral gene expression and replication through the proteolytic processing of replicase polyproteins. In this work, it has been investigated the junction of six inhibitors including N-[[4-(4-methylpiperazin-1-yl)phenyl]methyl]-1,2oxazole-5-carboxamide (INH1), NSC 158362 (INH2), JMF 1586 (INH3), (N-(2-aminoethyl)-11ziridine-ethanamine) (INH4), [(Z)-1-thiophen-2-ylethylideneamino]thiourea (INH5), and Vanillinbananin (INH6) to coronavirus by forming the complexes of inhibitor-CoV through the hydrogen bonding using the physicochemical properties of the heat of formation, Gibbs free energy, electronic energy, the charge distribution of active parts in the hydrogen bonding, NMR estimation of inhibitor jointed to the database amino acids fragment of Tyr-Met-His as the selective zone of the CoV, positive frequency and intensity of different normal modes of these structures. The theoretical calculations were done at various levels of theory to gain more accurate equilibrium geometrical results. A comparison of these structures with two configurations provides new insights for the design of substrate-based inhibitors targeting $\mathrm{CoV}$. This indicates a feasible model for designing wide-spectrum inhibitors against $\mathrm{CoV}$-associated diseases. The structure-based optimization of these structures has yielded two more efficacious lead compounds, $\mathrm{N}$ and $\mathrm{O}$ atoms, through forming the hydrogen bonding (H-bonding) with potent inhibition against CoV (Tyr160-Met161-His162), which has been abbreviated as TMH in this work.
\end{abstract}

Keywords: CoV; inhibitor; TMH; drug delivery; physicochemical properties; NMR; hydrogen bonding; IR; anti-coronavirus; H-bonding.

(C) 2021 by the authors. This article is an open-access article distributed under the terms and conditions of the Creative Commons Attribution (CC BY) license (https://creativecommons.org/licenses/by/4.0/).

\section{Introduction}

Coronaviruses (CoVs) are positive-stranded RNA viruses that cause a wide range of enteric and central nervous system diseases in multiple animal species, including humans [14].

Coronavirus disease 2019, COVID-19, is a contagious disease caused by SARS-CoV2 [5], close to the SARS virus [6-10], through tiny droplets from infected patients while they breathe or cough [11,12]. Between 2 and 14 days, the virus appears with few symptoms or develops fever, cough, and shortness of breath $[13,14]$, but it can be overcome by hygiene substances $[15,16]$.

$\mathrm{CoV}$ closely corresponds to intense breathing syndrome $\mathrm{CoV}$ (SARS-CoV), an epidemic with a short period of its living time. SARS-CoV and MERS-CoV relate to the family 
coronaviridae family as enveloped, positive-stranded RNA viruses with around 30,000 nucleotides. It has been reported that the global outbreak of typical life-threatening pneumonia caused about 800 deaths which were world identified as the harsh syndrome CoV (SARS-CoV) [17-21].

Moreover, developed investigations have indicated that the origin of SARS-CoV based on the phylogenic analysis is most likely from bats that are transferred to human aerosols due to intermediate hosts like infectious palm civets by the virus [22-24].

Thus, due to its power of intermediate transition into persons, animal disease is a threat that has been summarized with the novel MERS-CoV suggesting bats and dromedary camels as the storage for this virus [25-30].

Besides, MERS-CoV declares SARS-like symptoms due to human infections, including malaise, rigors, fatigues, and high fevers, signs like influenza, but it has been seen later development to typical pneumonia in most cases [31].

In some researches, it has been discovered that a prototype of the coronaviridae family is avian infectious bronchitis virus (IBV) which relates to the genetic group III of CoV and causes severe economic defeat for the poultry industry in the world [32-35].

Actually, the scientists have not discovered any vaccine or specific antiviral treatment by management concerning the care of symptoms, supportive treatment, and experimental data [36]. The results have shown the sample between $1 \%$ to $3 \%[37,38]$.

There are some recommendations from the World Health Organization (WHO) to suspected infectious persons having the coronavirus, including; wearing a surgical face mask and seeking medical advice from a doctor. Coronavirus disease was indicated with WHO as a Public Health Emergency of International Concern (PHEIC) in 2019-2020. Then China was declared a zone of the spread of this virus in 2020 [39-41].

So, in this project, the junction process of six inhibitors including N-[[4-(4-methyl piperazine-1-yl)phenyl]methyl]-1,2-oxazole-5-carboxamide $\quad$ (INH1), $\quad$ NSC 158362 (INH2),JMF 1586 (INH3), (N-(2-aminoethyl)-1-1ziridine-ethanamine) (INH4), [(Z)-1thiophen-2-ylethylideneamino] thiourea (INH5) and Vanillinbananin (INH6) to coronavirus by forming the complexes of Inhibitor- $\mathrm{CoV}$ (INH[1-6]-TM) through the hydrogen bonding (Hbonding) has been estimated using theoretical methods to measure the effect of H-bonding in the different linkage of six inhibitors to the chain of Tyr160-Met161-His162.

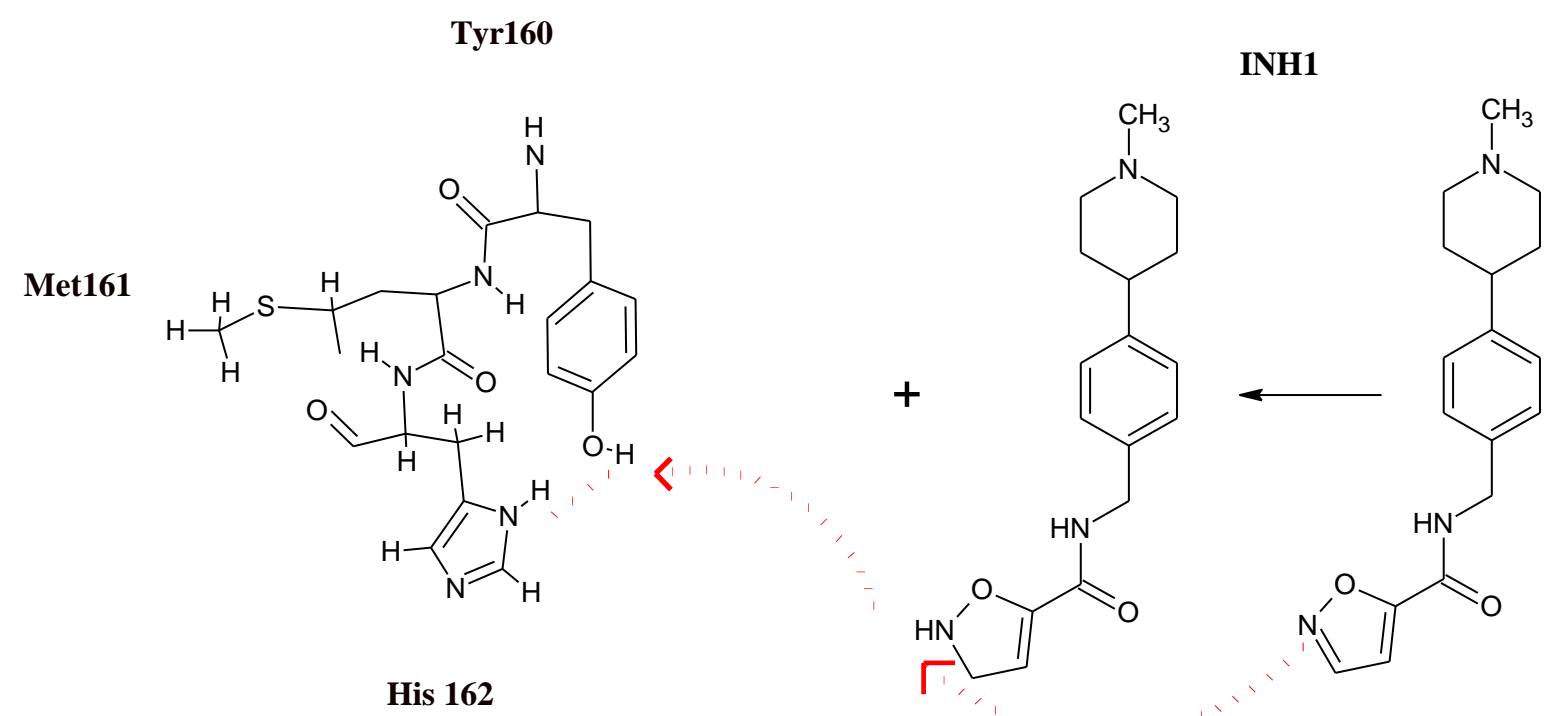




\section{Tyr160}

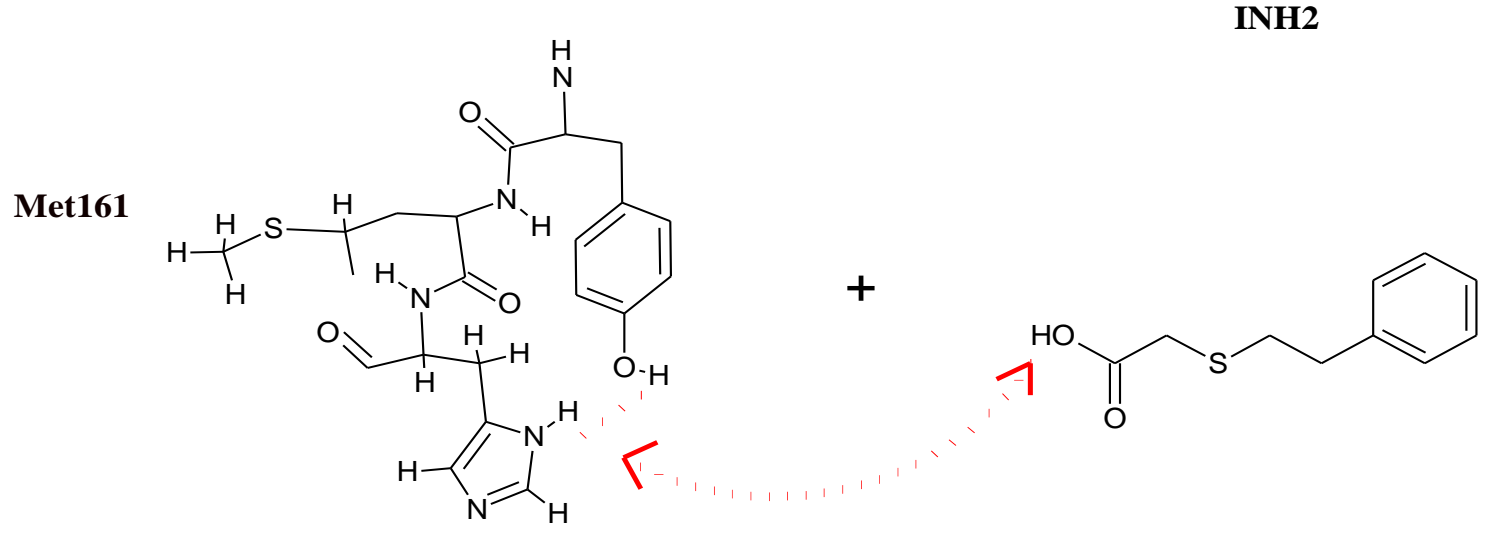

His 162

Tyr160

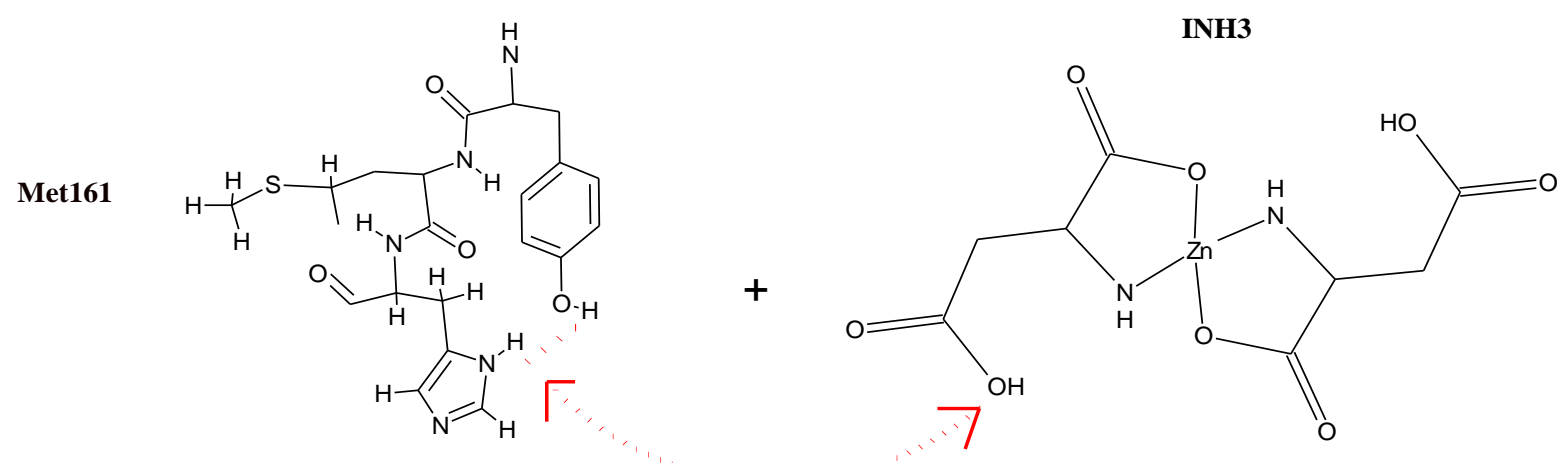

His 162

Tyr160

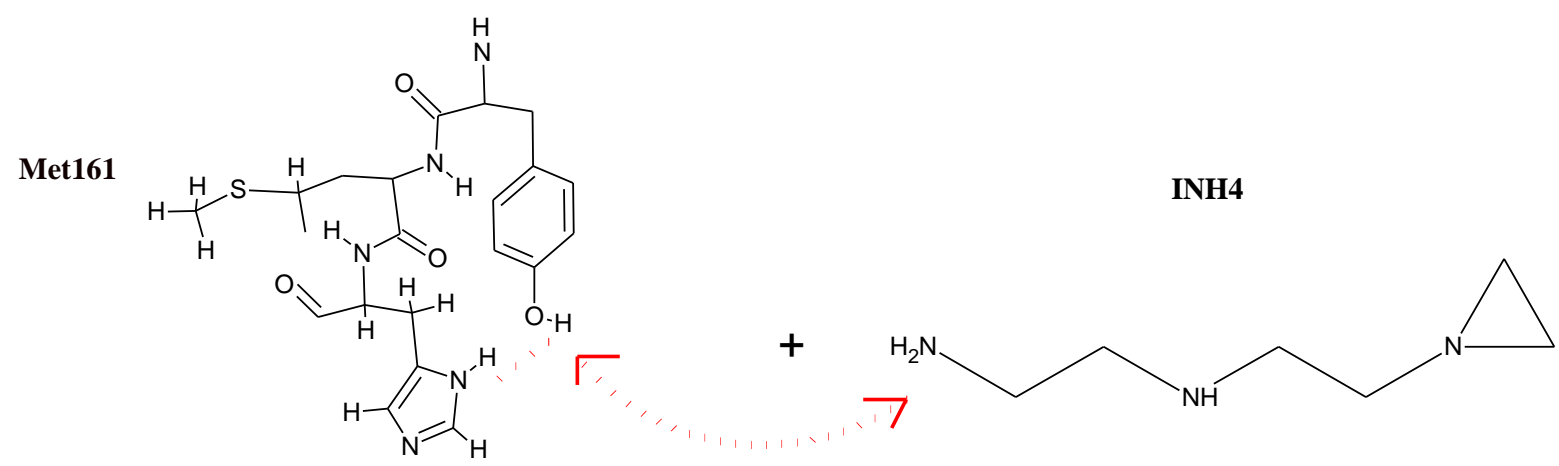

His 162 
<smiles>[H][Z]([H])(C)SC(C)CC(C(=O)N(C)C(C=O)C(C)c1c[nH]cc1[2H])N(C)C(=O)C(N)Cc1ccc(O)cc1</smiles>

His 162

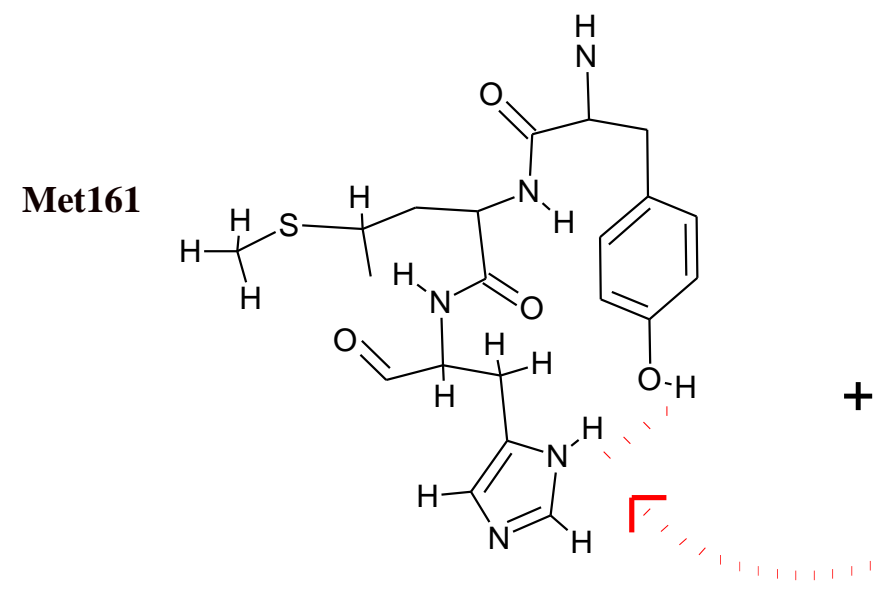

His 162
INH5

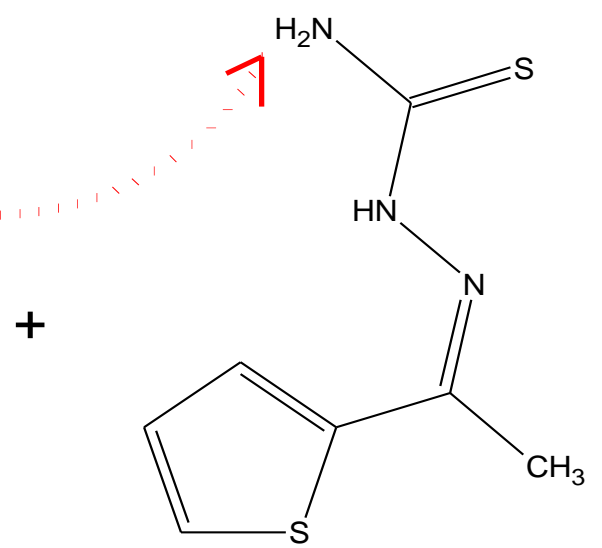

INH6

Scheme 1. The junction of N-[[4-(4-methylpiperazin-1-yl)phenyl]methyl]-1,2-oxazole-5-carboxamide (INH1), NSC 158362 (INH2),JMF 1586 (INH3),(N-(2-aminoethyl)-1-1ziridine-ethanamine) (INH4) ,[(Z)-1-thiophen-2ylethylideneamino]thiourea (INH5) and Vanillinbananin (INH6) to TMH (Tyr160-Met161-His162) by hydrogen bonding.

Then, the drug delivery method has been launched on the structures, which have been modeled and estimated by nuclear magnetic resonance (NMR) and calculated by infrared (IR) spectroscopy using Gaussian09 at 300K (Scheme 1).

\section{Materials and Methods}

The junction of N-[[4-(4-methylpiperazin-1-yl)phenyl]methyl]-1,2-oxazole-5-carboxamide (INH1), NSC 158362 (INH2), JMF 1586 (INH3), (N-(2-aminoethyl)-1-1ziridine-ethanamine) (INH4), [(Z)-1-thiophen-2-ylethylideneamino]thiourea (INH5) and Vanillinbananin (INH6) to TMH (Tyr160Met161-His162) has been studied in this investigation by forming relatively stable complexes through the H-bonding. Thus, a series of quantum-theoretical approaches of m062x/cc-pvdz pseudo=lanl2 for INH3 (JMF 1586) and pseudo=CEP for other complexes of INH [1-6]-TMH has been done due to finding the optimized coordination of the best structures of INH [1-6]Tyr160-Met161-His162 drug delivery model with IR computations using the Gaussian09 program package [42]. It has been declared that polarization functions into the applied basis set in the computation always introduce us to an important achievement on the modeling and 
simulation theoretical levels. Normal mode accomplishment is the verdict of potential harmonic wells by analytic methods that maintain all atoms' motion simultaneously in the vibration time scale, leading to a natural explanation of molecular vibrations [43-48].

Thus, the optimized geometry coordination of INH [1-6]-TMH complexes (Figure 1) toward the drug delivery method has been done by a series of quantum theoretical approaches of $\mathrm{m} 062 \mathrm{x} / \mathrm{cc}-\mathrm{pvdz}$ pseudo=lanl2 for INH3 (JMF 1586) and pseudo=CEP for other complexes using the Gaussian09 program package which has shown the active position of indicated oxygen, nitrogen and hydrogen atoms in the junction of bond angles including; $\mathrm{N}(44)-\mathrm{H}(67)$ $=\mathrm{O}(66), \mathrm{N}(73)-\mathrm{H}(74) \cdots \mathrm{O}(13), \mathrm{N}(77) \cdots \mathrm{H}(78)=\mathrm{O}(7), \mathrm{N}(10) \cdots \mathrm{H}(44) \cdots \mathrm{O}(43)$, $\mathrm{N}(17)=\mathrm{H}(44)=\mathrm{O}(43), \mathrm{N}(86)-\cdots \mathrm{H}(87)-\cdots \mathrm{O}(7)$ for INH[1-6]-TMH, respectively [42] (Table 1).
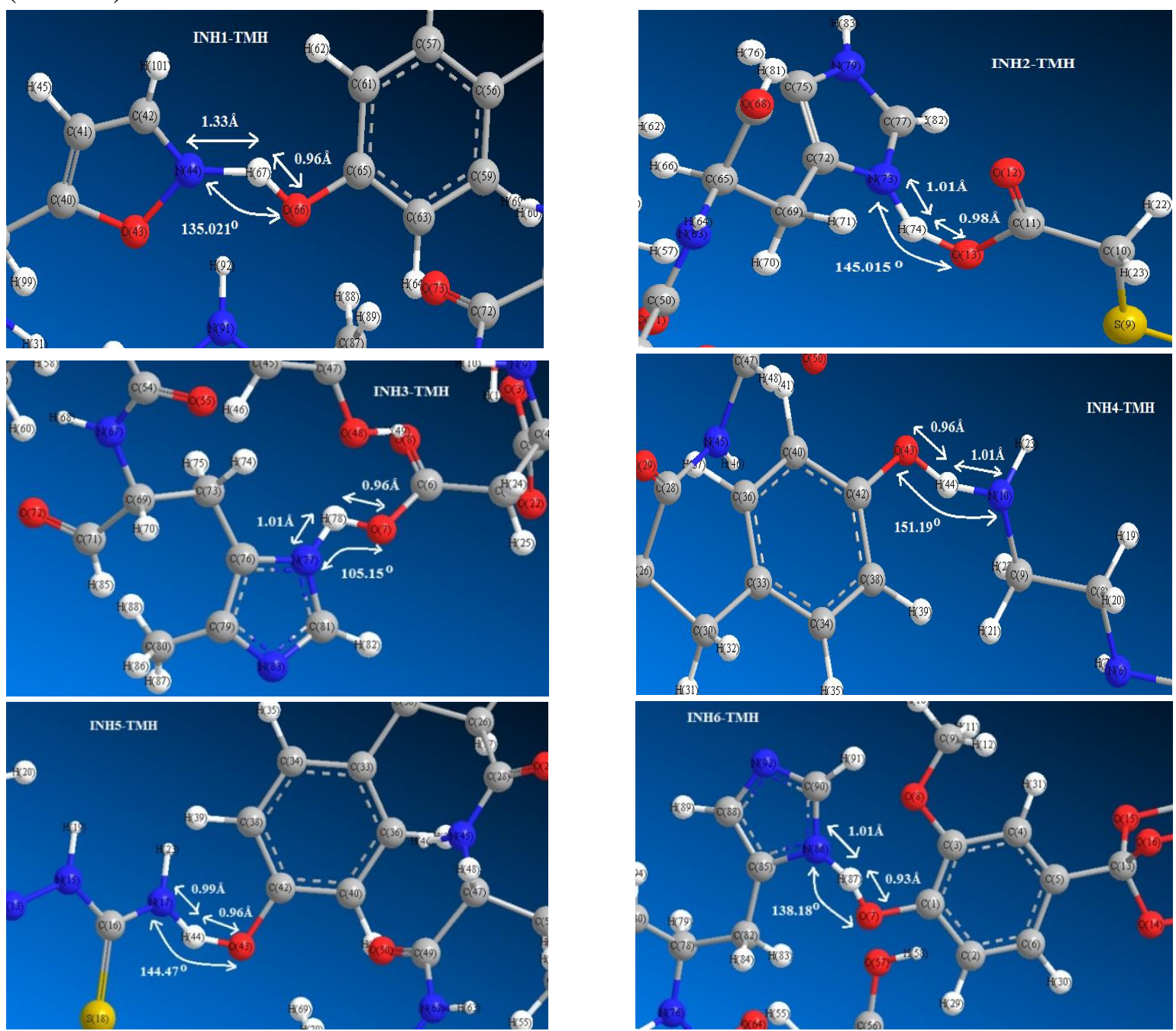

Figure 1. Optimized ab-initio geometry of INH [1-6]-TMH complexes through the drug delivery method through representing the bond length of $\mathrm{N} \cdots \mathrm{H}, \mathrm{H} \cdots \mathrm{O}$ and bond angle of $\mathrm{N} \cdots \cdots \mathrm{H}-\mathrm{O}$ - calculated by $\mathrm{m} 062 \mathrm{x} / \mathrm{cc}-\mathrm{pvdz}$ pseudo=lanl2 for INH3 (JMF 1586) and pseudo=CEP for other complexes.

Table 1. Optimized geometry with m062x/cc-pvdz pseudo=lanl2 for INH3 (JMF 1586) and pseudo=CEP for other complexes, INH [1,2-6]-TMH ,using the drug delivery method.

\begin{tabular}{|c|c|c|c|c|}
\hline INH-CoVs & Bond length & $(\AA)$ & Bond angle & $\left({ }^{\circ}\right)$ \\
\hline \multirow{2}{*}{ INH1-TMH } & $\mathrm{N}(44) \stackrel{\cdots}{-} \mathrm{H}(67)$ & 1.33076 & \multirow{2}{*}{$\mathrm{N}(44) \stackrel{\cdots}{-} \mathrm{H}(67) \stackrel{\cdots}{-} \mathrm{O}(66)$} & \multirow{2}{*}{135.021} \\
\hline & $\mathrm{H}(67) \stackrel{\cdots}{-} \mathrm{O}(66)$ & 0.960771 & & \\
\hline \multirow{2}{*}{ INH2- TMH } & $\mathrm{N}(73) \stackrel{\cdots}{-} \mathrm{H}(74)$ & 1.01017 & \multirow{2}{*}{$\mathrm{N}(73) \stackrel{-\cdots}{-} \mathrm{H}(74) \stackrel{-\cdots}{-} \mathrm{O}(13)$} & \multirow{2}{*}{145.015} \\
\hline & $\mathrm{H}(74)=\mathrm{O}(13)$ & 0.984098 & & \\
\hline \multirow{2}{*}{ INH3- TMH } & $\mathrm{N}(77) \stackrel{\mathrm{H}(78)}{-}$ & 1.01017 & \multirow{2}{*}{$\mathrm{N}(77) \stackrel{\mathrm{H}(78)}{-} \mathrm{O}(7)$} & \multirow{2}{*}{105.147} \\
\hline & $\mathrm{H}(78) \stackrel{\cdots}{=} \mathrm{O}(7)$ & 0.957995 & & \\
\hline
\end{tabular}




\begin{tabular}{|c|c|c|c|c|}
\hline INH-CoVs & Bond length & (§̊) & Bond angle & $\left({ }^{\circ}\right)$ \\
\hline \multirow{2}{*}{ INH4- TMH } & $\mathrm{N}(10) \cdots \cdots+\mathrm{H}(44)$ & 1.01616 & \multirow{2}{*}{$\mathrm{N}(10) \stackrel{\cdots}{-} \mathrm{H}(44) \stackrel{\cdots}{-} \mathrm{O}(43)$} & \multirow{2}{*}{151.195} \\
\hline & $\mathrm{H}(44) \stackrel{\cdots}{-\cdots} \mathrm{O}(43)$ & 0.960771 & & \\
\hline \multirow{2}{*}{ INH5- TMH } & $\mathrm{N}(17) \cdots \cdots+\cdots(44)$ & 0.990522 & \multirow{2}{*}{$\mathrm{N}(17) \stackrel{\cdots}{-} \mathrm{H}(44) \stackrel{\cdots}{-} \mathrm{O}(43)$} & \multirow{2}{*}{144.474} \\
\hline & $\mathrm{H}(44) \cdots \mathrm{O}(43)$ & 0.960771 & & \\
\hline \multirow{2}{*}{ INH6- TMH } & $\mathrm{N}(86) \cdots \cdots+\cdots(87)$ & 1.01017 & \multirow{2}{*}{$\mathrm{N}(86) \stackrel{\cdots}{\cdots} \mathrm{H}(87) \stackrel{\cdots}{\cdots} \mathrm{O}(7)$} & \multirow{2}{*}{138.178} \\
\hline & $\mathrm{H}(87) \cdots \mathrm{O}(7)$ & 0.929103 & & \\
\hline
\end{tabular}

Besides, the data has been achieved from thermodynamic parameters of $\Delta \mathrm{G}, \Delta \mathrm{H}$, and $\Delta \mathrm{S}$ for INH [1-6] - Tyr160-Met161-His162 drug delivery.

Therefore, for accomplishing a stable structure of INH [1-6] linkage of Tyr160Met161-His162, geometry optimization plus the NMR estimation, the frequency and intensity of the vibrational modes were calculated with the quantum mechanical (QM) theoretical method, and the principal vibrational modes were analyzed by their changes of Gibbs free energy in water medium at $300 \mathrm{~K}$.

Thermodynamic experiments conduct the frequency and normal mode results. The energy in Gaussian09 has been expanded and corrected as thermal correction to energy, thermal correction to enthalpy, and thermal correction to the Gibbs free. In addition, the total energies can be calculated as the sum of electronic and zero-point energies, the sum of electronic and thermal energies, the sum of electronic and thermal enthalpies, and the sum of electronic and thermal Gibbs free energies.

The theoretical calculations were done at various levels of theory to gain more accurate equilibrium geometrical results and IR spectral data for each of the identified compounds. It is supposed that an additional diffuse and polarization functions into the basis set applied in the computation conduct us to the magnificent progress on the results of theoretical methods. The simulation indicates the approaches which produce a common template of a model at a special temperature by computing all physicochemical properties among the partition function [44].

Each part of the systems including INH[1-6]-TMH has been optimized using ab-initio via density functional theory, including ECP calculations with lanl2 for INH3 (JMF 1586) and pseudo=CEP for INH[1,2-6]) basis sets. In addition, those systems have been evaluated via QM/MM approach through an ONIOM method. In our study, differences of force fields are debated through comparing density and energies with OPLS and AMBER via Monte Carlo optimization. In addition, a Hyperchem professional release 7.01 program has been applied for some additional keywords such as PM3MM, PM6 (pseudo=lanl2 for INH3 (JMF 1586), and pseudo=CEP for INH [1, 2-6]) [49, 50].

The DFT with the van der Waals densities functional were investigated for modeling of solvent-compounds interaction. All optimization of solvent effects was done by Gaussian 09. The accurate calculations were performed using m062x, m06-L, and m06 for the junction of the inhibitor to database amino acids interaction. The m062x, m06-L, and m06-HF methods have a suitable correspondence in non-bonded calculations between these compounds and solvents. The ONIOM levels have been applied through three levels of high $(\mathrm{H})$, medium $(\mathrm{M})$, and low (L) calculations, while DFT methods were used for the high $(\mathrm{H})$ layer and the semiempirical method of pm6 and Pm3MM was used for the medium and finally Monte Carlo for low layers, respectively. The Polarizable Continuum Model, PCM, is the most popular SCRF model based on apparent surface charges expanding to discuss non-electrostatic impacts using scaled point theory $[51,52]$.

Rinaldi and Rivail developed the most common levels of the SCRF method of multiple expansions with an algorithm based on the use of a strict multipolar expansion up to the 7th 
order by Frisch that is currently available at both semi-empirical and ab initio levels of theory [53-55]. Onsager and Kirkwood have arranged an intention for various continuum solvation examples of a multiple expansion, MPE, of the solute charge distribution [56-58]. Then, Wiberg and co-workers improved Onsager-SCRF for the Gaussian program $[59,60]$.

Solvation is illustrated in terms of a dipole moment with an iterative path of quantum mechanics calculations on the structure. The perspective of Onsager-SCRF was one to directly apply almost all of the Gaussian program's computational characteristics. The dielectric continuum models like the self-consistent reaction field approach are efficient in applying account the long-range of solute-solvent electrostatic interactions and the effect of solvent polarization. Another theoretical level is the combination of molecular mechanics (MM) solvent molecule with quantum mechanics level (QM) for the electronic structure of the solute molecule named QM/MM, which can modify a deficiency of the dielectric continuum model $[61,62]$.

\section{Results and Discussion}

NMR calculations on the database of amino acids in the beta-sheet conformation of Tyr160-Met161-His 162 and six inhibitors of N-[[4-(4-methylpiperazin-1-yl)phenyl]methyl]1,2-oxazole-5-carboxamide (INH1), NSC 158362 (INH2), JMF 1586 (INH3),(N-(2aminoethyl)-1-1ziridine-ethanamine) (INH4), [(Z)-1-thiophen-2-ylethylideneamino]thiourea (INH5) and Vanillinbananin (INH6) have been estimated to unravel the indicated atoms of $\mathrm{H}$, $\mathrm{N}, \mathrm{O}$ in the active sites of these anti-virus drugs through the formation of hydrogen bonding by indicating the attack zone of TMH (Scheme 2a-g).

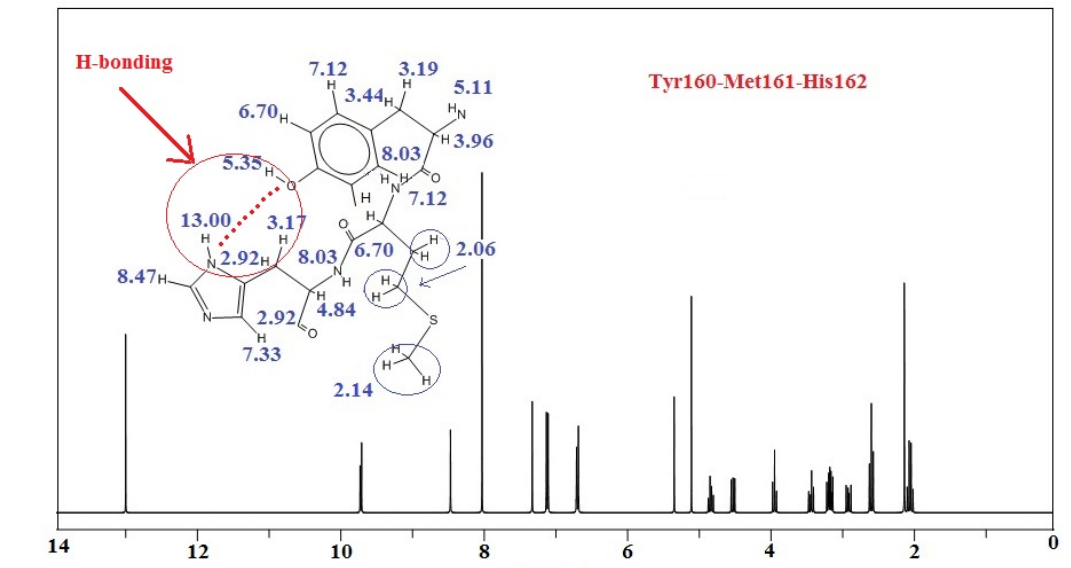

(a)

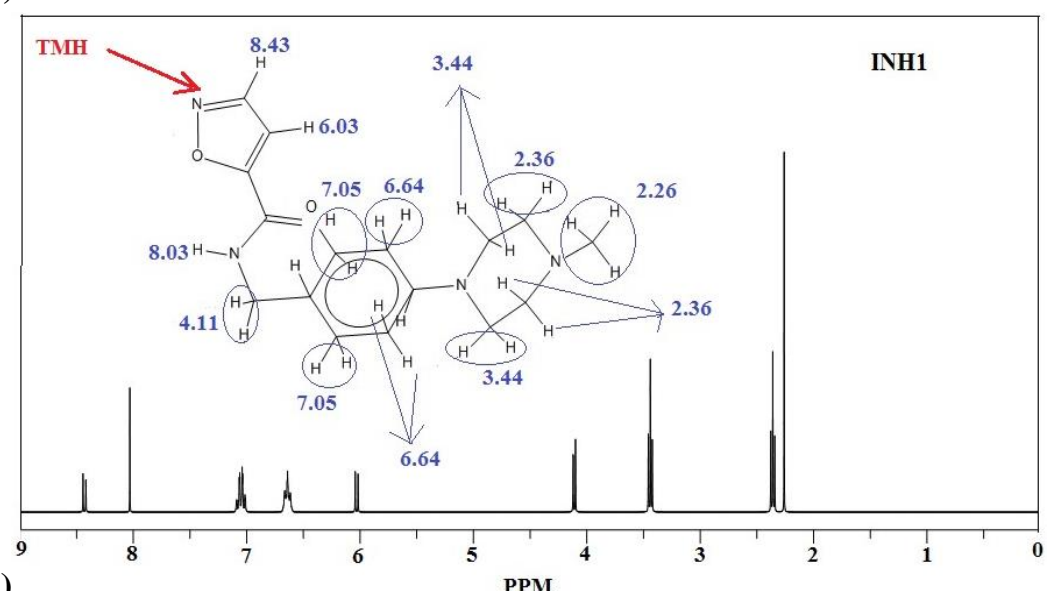

(b) 


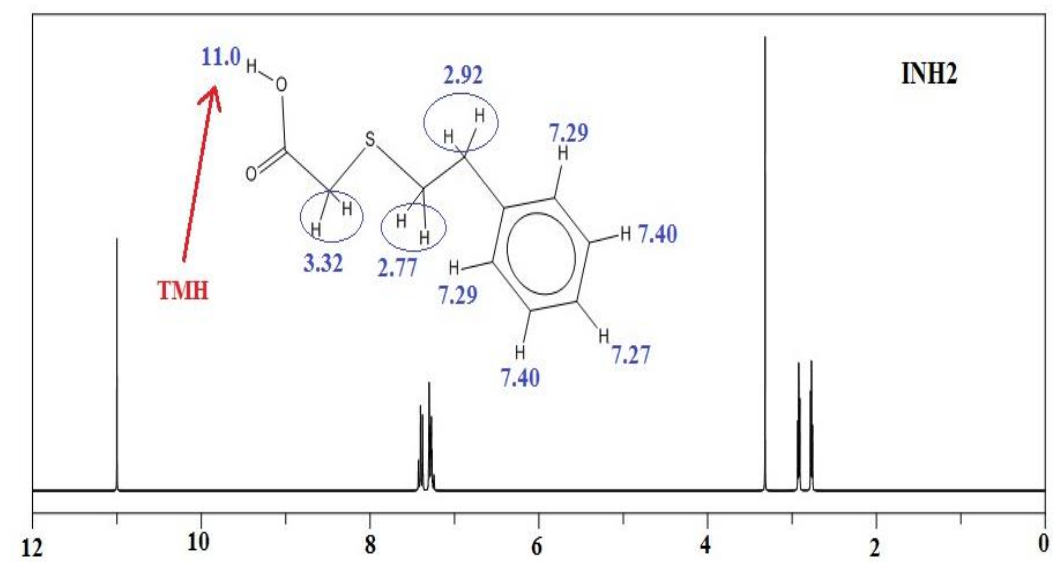

(c)

PPM

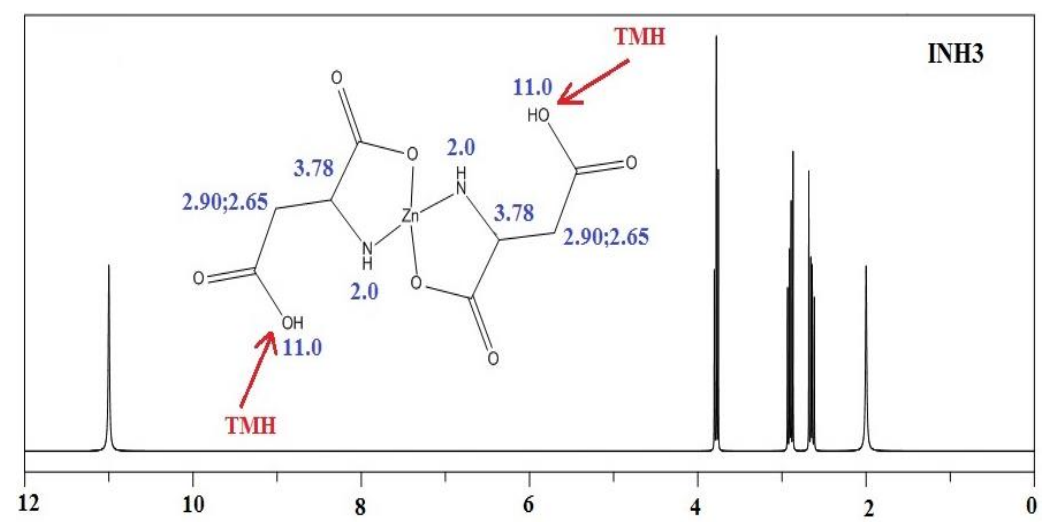

(d)

PPM

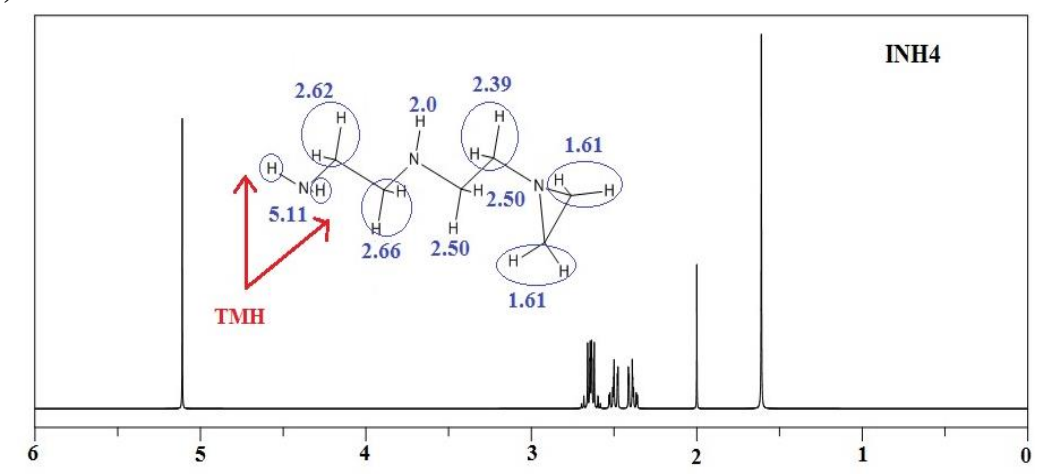

(e)

PPM

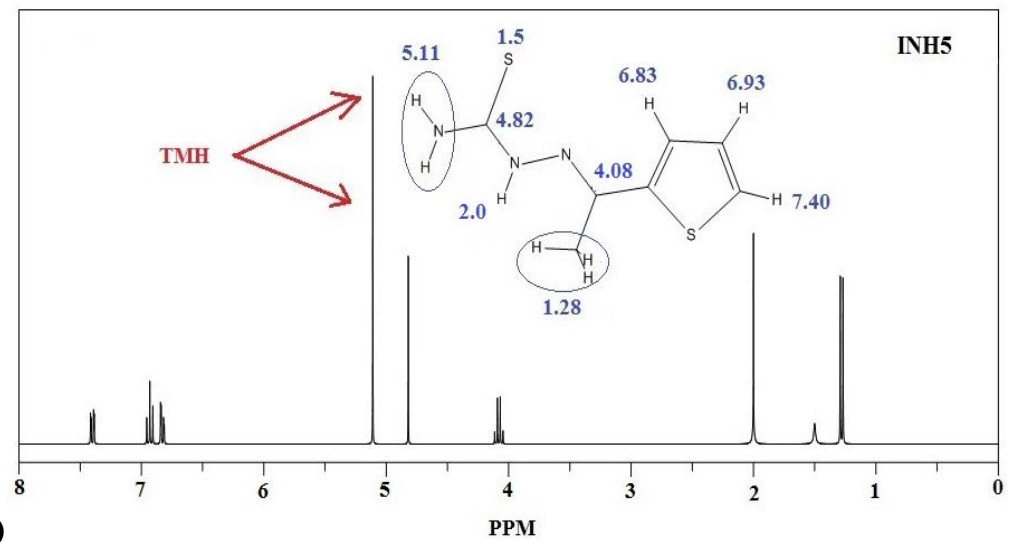




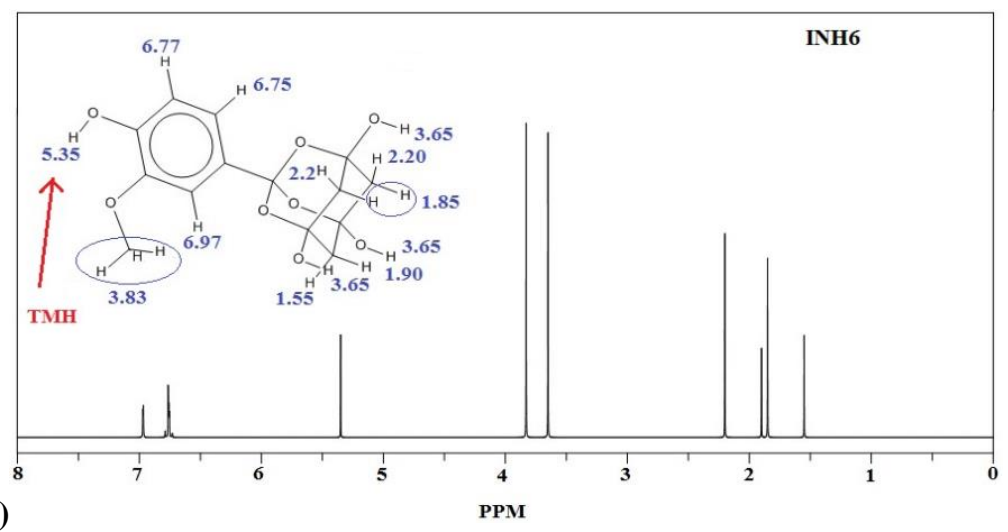

Scheme 2. NMR spectra of (a) Tyr160-Met161-His162; (b)N-[[4-(4-methylpiperazin-1-yl)phenyl]methyl]-1,2oxazole-5-carboxamide (INH1); (c) NSC 158362 (INH2); (d) JMF 1586 (INH3), (e) (N-(2-aminoethyl)-11ziridine-ethanamine) (INH4); (f) [(Z)-1-thiophen-2-ylethylideneamino]thiourea (INH5); (g) Vanillinbananin (INH6) by indicating the active zone of TMH in the drug delivery process.

The NMR measurements demonstrate the active sites of the inhibitors for linking to the Tyr160-Met161-His162 (TMH) in forming the anti-virus drugs while each active atom of oxygen and nitrogen as the electronegative atoms for attaching to the hydrogen denotes the maximal shift in all levels in the NMR spectra (Scheme 2).

Table 2. Thermodynamic properties of INH-CoVs complexes; NHI[1-6]-TMH at $300 \mathrm{~K}$.

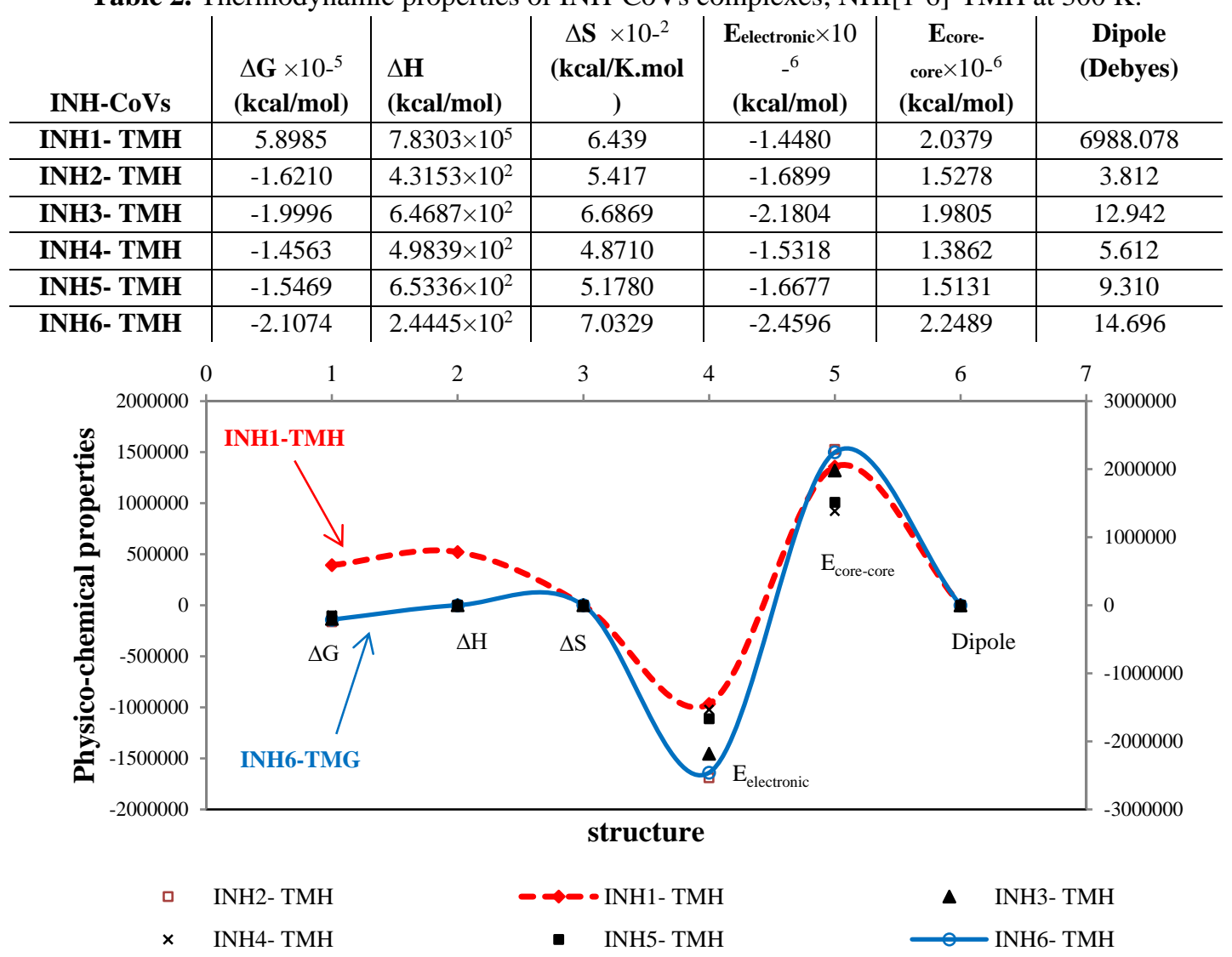

Figure 2. Changes of physicochemical properties of $\Delta \mathrm{G}, \Delta \mathrm{H}, \Delta \mathrm{S}, \mathrm{E}_{\text {electronic }}$, and $\mathrm{E}_{\text {Core-Core }}$ for the stable anticoronavirus complexes of INH [1-6]-TMH through the H-bonding formation using the drug delivery method.

In this project, six inhibitors of $\mathrm{N}$-[[4-(4-methylpiperazin-1-yl)phenyl]methyl]-1,2oxazole-5-carboxamide (INH1), NSC 158362 (INH2), JMF 1586 (INH3),(N-(2-aminoethyl)1-1ziridine-ethanamine) (INH4), [(Z)-1-thiophen-2-ylethylideneamino]thiourea (INH5) and Vanillinbananin (INH6) have been estimated for stabilizing the junction of Tyr160-Met161- 
His 162 as the anti-coronavirus through the drug delivery method using IR spectroscopy using Gaussian09 (Figure 1).

Therefore, the thermodynamic properties of $\Delta \mathrm{G}, \Delta \mathrm{H}, \Delta \mathrm{S}$, Electronic Energy, and CoreCore interaction have determined the stable anti-coronavirus complexes of INH[1-6]-TMH through the H-bonding formation using the drug delivery method (Table2 and Figure 2) [42].

Moreover, the difference of $\Delta \mathrm{H}_{\mathrm{F}}$ among INH[1-6] - TMH has discussed the H-bonding through the six types of inhibitors jointed to the database of amino acids in beta-sheet conformation; Tyr160-Met161-His162 as the active site of the coronavirus (CoV) families (Table 3, Figure 3).

Table 3. The Heat of formation, $\Delta \mathrm{H}_{\mathrm{F}}$, among INH[1-6] -TMH (kcal/mol)

\begin{tabular}{|c|c|c|c|}
\hline \multirow{5}{*}{ 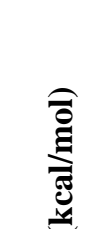 } & $\Delta \mathbf{H}_{\text {INH1 }}$ & $\Delta \mathbf{H}_{(\text {INH1-TMH) }}$ & $\Delta \mathbf{H}_{\mathrm{F}}=\Delta \mathbf{H}_{(\text {INH1-TMH })}-\left(\Delta \mathrm{HTMH}_{\mathrm{T}}+\Delta \mathrm{H}_{\text {INH1 }}\right)$ \\
\hline & 1756.0324114 & 783032.8395052 & 523034.2056861 \\
\hline & $\Delta \mathbf{H}_{\text {INH2 }}$ & $\Delta \mathbf{H}_{(\text {INH2-TMH) }}$ & $\Delta \mathbf{H}_{\mathrm{F}}=\Delta \mathbf{H}_{(\mathrm{INH} 2-\mathrm{TMH})}-\left(\Delta \mathbf{H}_{\mathrm{TMH}}+\Delta \mathbf{H}_{\mathrm{INH} 2}\right)$ \\
\hline & 2.1157530 & 431.5301077 & -257813.187053 \\
\hline & $\Delta \mathbf{H}_{\text {INH3 }}$ & $\Delta \mathbf{H}_{(\text {INH3-TMH) }}$ & $\Delta \mathbf{H}_{\mathrm{F}}=\Delta \mathbf{H}_{(\text {INH3-TMH })}-\left(\Delta \mathbf{H}_{\text {TMH }}+\Delta \mathbf{H}_{\text {INH3- }}\right)$ \\
\hline \multirow{7}{*}{ 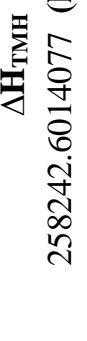 } & 102.5596807 & 646.8767409 & -257698.2843475 \\
\hline & $\Delta \mathbf{H}_{\text {INH4 }}$ & $\Delta \mathbf{H}_{(\text {INH4-TMH) }}$ & $\Delta H_{F}=\Delta H_{(\text {INH4-TMH })}-\left(\Delta\right.$ HTMH $\left.+\Delta H_{\text {INH4 }}\right)$ \\
\hline & 121.9099699 & 498.3960408 & -257866.1153368 \\
\hline & $\Delta \mathbf{H}_{\text {INH5 }}$ & $\Delta \mathbf{H}_{\text {( INH5-TMH) }}$ & $\Delta \mathbf{H}_{\mathrm{F}}=\Delta \mathrm{H}_{(\text {INH5-TMH })}-\left(\Delta \mathrm{H}_{\text {TMH }}+\Delta \mathrm{H}_{\text {INH5 }}\right)$ \\
\hline & 122.5763148 & 653.3642056 & -257711.8135169 \\
\hline & $\Delta \mathbf{H}_{\text {INH6 }}$ & $\Delta \mathbf{H}_{(\text {INH6-TMH) }}$ & $\Delta \mathbf{H}_{\mathrm{F}}=\Delta \mathrm{H}_{(\mathrm{INH6}} \mathrm{TMH}-\left(\Delta \mathrm{H}_{\mathrm{TMH}}+\Delta \mathrm{H}_{\mathrm{INH6}}\right)$ \\
\hline & -273.6391946 & 244.4522546 & -257724.5099585 \\
\hline
\end{tabular}

In all six types of inhibitors jointed to the database of amino acids in beta-sheet conformation, Tyr160-Met161-His162, as the active site of the coronavirus(CoV) families in the process of drug delivery, the frequency and intensity of various infrared normal modes of INH[1-6]-TMH complexes have been found to be significantly different through the stability of H-bonding formed between the active site of $\mathrm{CoV}$ and inhibitors which founds the anticoronavirus (Table 4, Figure 4).

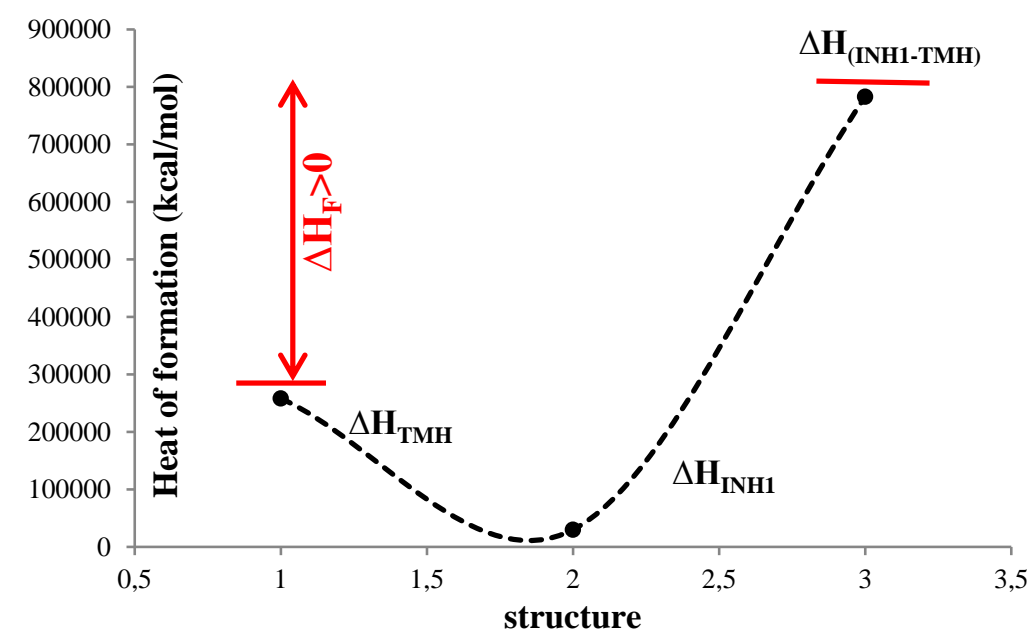

(a) 


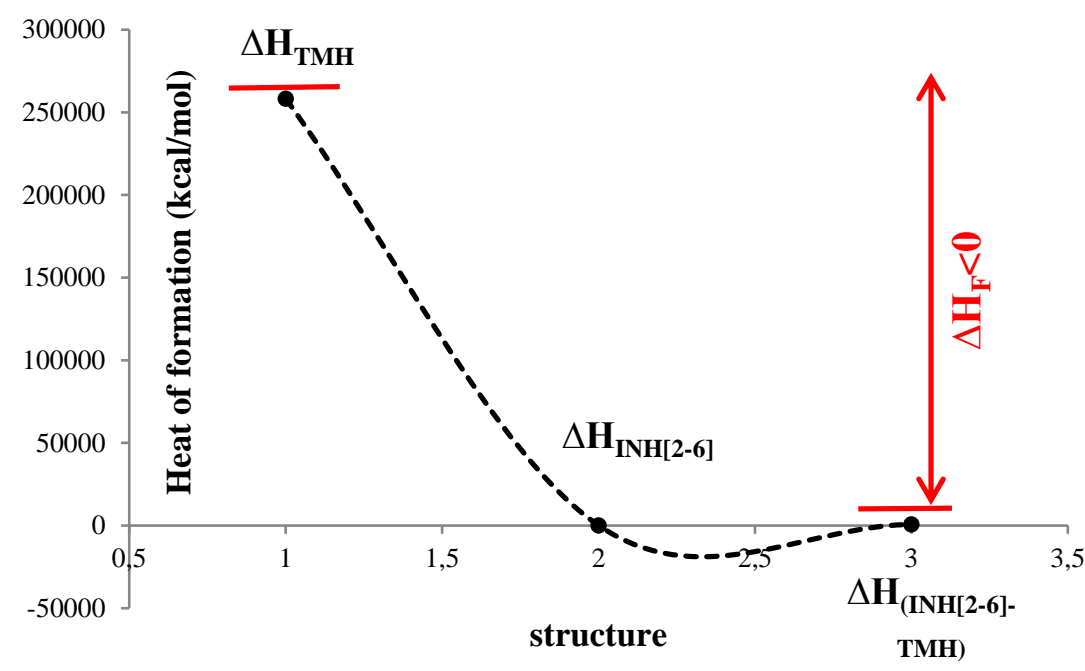

(b)

Figure 3. The difference of $\Delta \mathrm{H}_{\mathrm{F}}$ among (a) INH1-TMH; (b) INH [2-6]-TMH.

Table 4.Calculated frequency and intensity of INH [1-6] -TMH in different normal modes of infrared spectra.

\begin{tabular}{l|l|l|l|l} 
Inhibitor & Complex & $\begin{array}{l}\text { Normal } \\
\text { mode }\end{array}$ & $\begin{array}{l}\text { Frequenc } \\
\mathbf{y}(\mathbf{1} / \mathbf{c m})\end{array}$ & $\begin{array}{l}\text { Intensity } \\
(\mathbf{k m} / \mathbf{m o l})\end{array}$ \\
\hline $\begin{array}{l}\text { N-[[4-(4-methylpiperazin-1- } \\
\text { yl)phenyl]methyl]-1,2-oxazole-5- } \\
\text { carboxamide }\end{array}$ & $\begin{array}{l}\text { (INH1- } \\
\text { TMH) }\end{array}$ & 288 & 7357.36 & 4354666.00 \\
\hline NSC 158362 & $\begin{array}{l}\text { (INH2- } \\
\text { TMH) }\end{array}$ & 231 & 5285.11 & 986.7394 \\
\hline JMF 1586 & $\begin{array}{l}\text { (INH3- } \\
\text { TMH) }\end{array}$ & 243 & 5285.71 & 752.0885 \\
\hline (N-(2-aminoethyl)-1-1ziridine-ethanamine) & $\begin{array}{l}\text { (INH4- } \\
\text { TMH) }\end{array}$ & 228 & 5284.54 & 1222.6909 \\
\hline $\begin{array}{l}\text { [(Z)-1-thiophen-2- } \\
\text { ylethylideneamino]thiourea }\end{array}$ & $\begin{array}{l}\text { (INH5- } \\
\text { TMH) }\end{array}$ & 219 & 5295.18 & 20233.9316 \\
\hline Vanillinbananin & $\begin{array}{l}\text { (INH6- } \\
\text { TMH) }\end{array}$ & 270 & 5285.84 & 751.2703
\end{tabular}

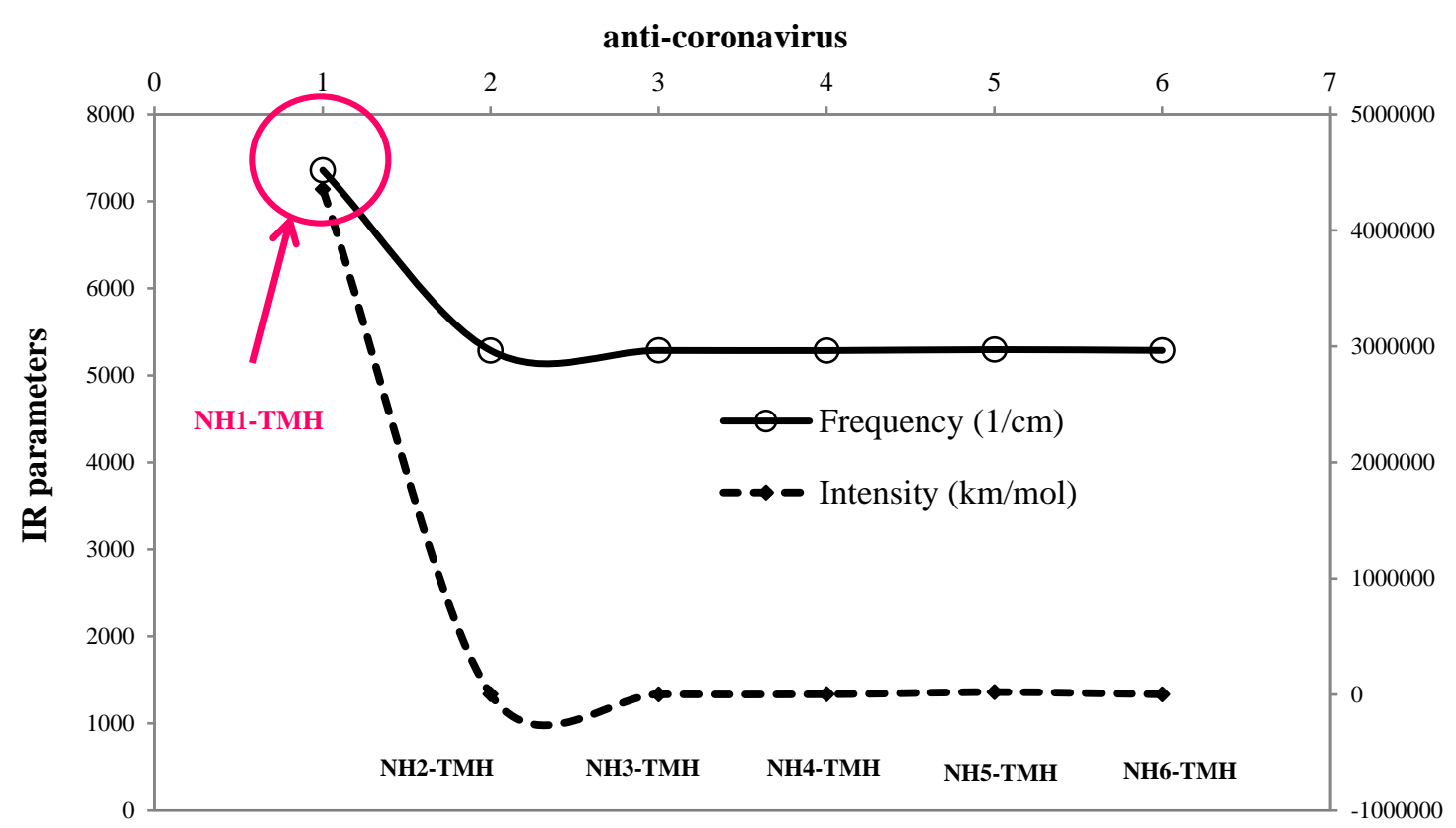

Figure 4. Changes of calculated frequency and intensity versus anti-coronavirus drugs of INH [1-6] -TMH in different normal modes of infrared spectra. 
The frequency and intensity TMH-junction were found to be significantly different with each inhibitor treatment including; $\mathrm{N}$-[[4-(4-methylpiperazin-1-yl) phenyl] methyl]-1,2oxazole-5-carboxamide, NSC 158362, JMF 1586, (N-(2-aminoethyl)-1-1ziridine-ethanamine), [(Z)-1-thiophen-2-ylethylideneamino] thiourea and Vanillinbananin as (INH [1-6]).

It has been seen that by increasing the activity of atoms in the active site of inhibitors, the frequency and intensity of INH [1-6]-Tyr160-Met161-His162 junction also have increased from 5285.84 to $7357.361 / \mathrm{cm}$ and from 751.2703 to $4354666.00 \mathrm{~km} / \mathrm{mol}$, respectively, with forming hydrogen bonding (Table 4, Scheme2 ).

Although we have little information about the interaction of inhibitors with $\mathrm{CoV}$, database amino acids fragment of Tyr160-Met161-His162 as the CoV's selective zone were found to induce spectra frequency and intensity.

The maximum positive frequency and intensity have been shown for $\mathrm{N}-[[4-(4-$ methylpiperazin-1-yl)phenyl]methyl]-1,2-oxazole-5-carboxamide(7357.36 $1 / \mathrm{cm} \quad$ and $4354666.00 \mathrm{~km} / \mathrm{mol}$ ) jointed to the database of amino acids in beta-sheet conformation (Tyr160-Met161-His162) with the abbreviation of (INH1-TMH) which has the largest amount as the anti-coronavirus in the spectrum data (Table 4, Figure 4).

Similar trends occurred in other INH [2-6]-TMH complexes exhibit the smallest changes in the infrared spectra where the $\mathrm{F}_{\max }$ of the junction for NSC 158362, JMF 1586, (N(2-aminoethyl)-1-1ziridine-ethanamine), and Vanillinbananin were 5285.11, 5285.71, $5284.54,5295.18$, and $5285.841 / \mathrm{cm}$, respectively (Fig.4). The intensity of IR spectra for NSC 158362, JMF 1586, (N-(2-aminoethyl)-1-1ziridine-ethanamine), and Vanillinbananin were reported as 986.7394, 752.0885, 1222.6909, 20233.9316, and $751.2703 \mathrm{~km} / \mathrm{mol}$, respectively, which have approved the stability of these structures anti-coronavirus using the drug delivery method (Table 4).

The frequency achieved of IR vibrational spectra have shown that the normal mode of the active sites due to $\mathrm{F}_{\max }$ for TMH linked to inhibitors of N-[[4-(4-methylpiperazin-1-yl) phenyl] methyl]-1,2-oxazole-5-carboxamide, NSC 158362, JMF 1586, (N-(2-aminoethyl)-11ziridine-ethanamine), [(Z)-1-thiophen-2-ylethylideneamino] thiourea and Vanillinbananin were reported 288,231,243,228,219, and 270, respectively (Table 4).

In the next step, the atomic charge of indicated atoms of oxygen, nitrogen, and hydrogen in the junction of N-[[4-(4-methylpiperazin-1-yl) phenyl] methyl]-1,2-oxazole-5carboxamide, NSC 158362, JMF 1586, (N-(2-aminoethyl)-1-1ziridine-ethanamine), [(Z)-1thiophen-2-ylethylideneamino] thiourea and Vanillinbananin with Tyr160-Met161-His 162 have been evaluated in the zone of H-bonding formation (Figure 1, Table 5).

Then, in Fig.5, it has been plotted the changes of atomic charge for labeled oxygen, nitrogen, and hydrogen atoms through optimized INH[1-6]-TMH complexes (Figure 1) due to the formation of H-bonding; so, the results of Table 5 in a polar zone have declared the stability of anti-coronavirus drugs which have been modeled using the drug delivery method. The largest fluctuation in Fig.5 has been seen for the sample of N-[[4-(4-methylpiperazin-1-yl) phenyl] methyl]-1,2-oxazole-5-carboxamide- Tyr160-Met161-His162 (INH1-TMH) considering the oxygen and nitrogen as the electronegative atoms and hydrogen in the formation of the H-bonding through using the drug delivery method which has proposed the modeling of anti-coronavirus. These results have approved the values of IR spectra for INH1TMHin and INH [2-6] TMH in Table 4 \& Figure 4.

Table 5. The amounts of atomic charge for labeled oxygen, nitrogen and hydrogen atoms in the junction of $\mathrm{N}$ -

[[4-(4-methylpiperazin-1-yl) phenyl] methyl]-1,2-oxazole-5-carboxamide, NSC 158362, JMF 1586, (N-(2- 
aminoethyl)-1-1ziridine-ethanamine), [(Z)-1-thiophen-2-ylethylideneamino] thiourea and Vanillinbananin with Tyr160-Met161-His162 (INH[1-6]-TMH).

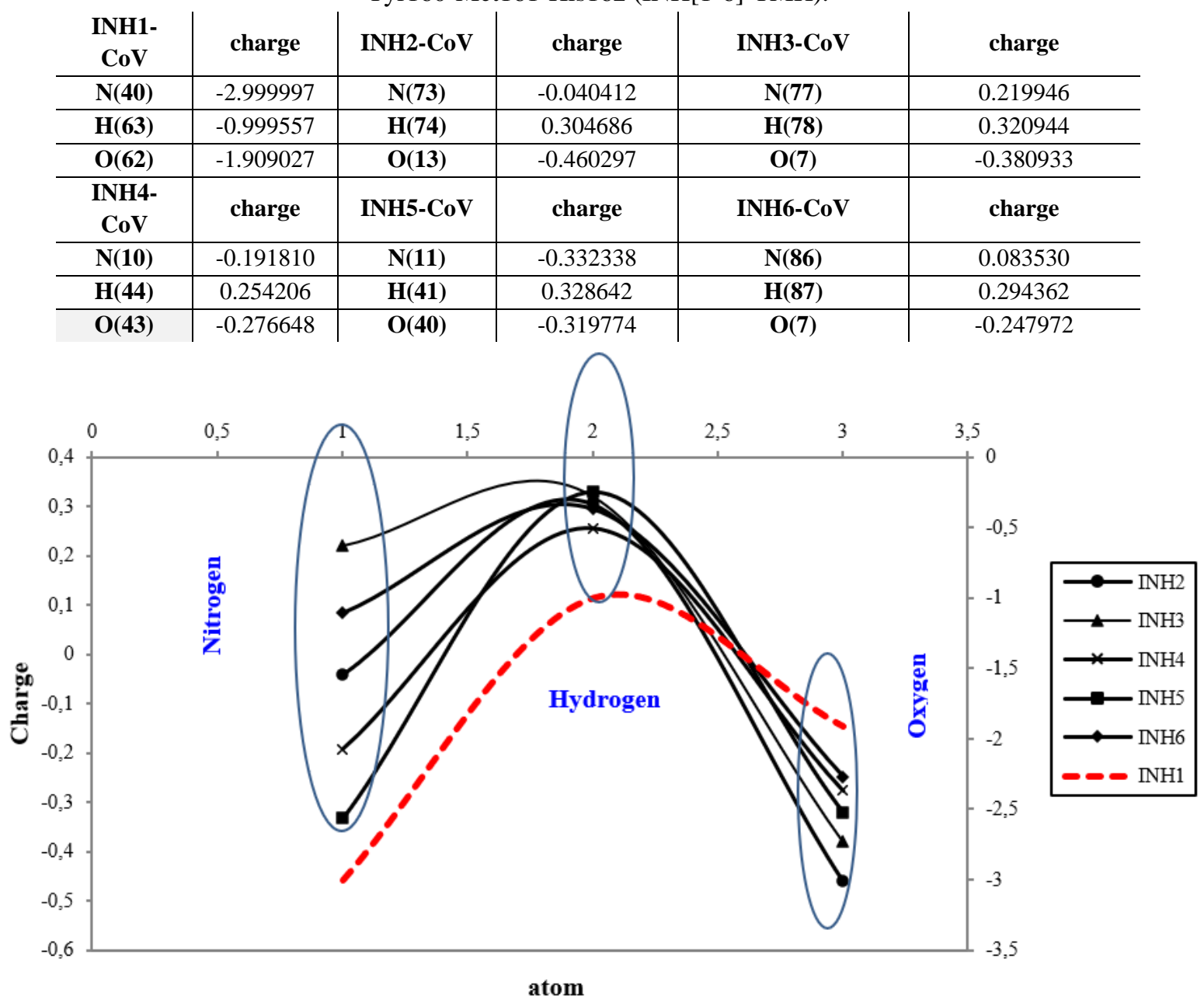

Figure 5. Comparison of atomic charge versus labeled of oxygen, nitrogen and hydrogen atoms in the junction of N-[[4-(4-methylpiperazin-1-yl) phenyl] methyl]-1,2-oxazole-5-carboxamide, NSC 158362, JMF 1586, (N-(2aminoethyl)-1-1ziridine-ethanamine), [(Z)-1-thiophen-2-ylethylideneamino] thiourea and Vanillinbananin with Tyr160-Met161-His162 (INH[1-6]-TMH).

Thus the perspective of Figure 5 has recommended the reason for existing observed various results of the atomic charge on INH[1-6]-TMH complexes as the inhibitor-coronavirus which are principally related to the position of active cites of indicated oxygen, nitrogen and hydrogen atoms in the junction of bond angles including; $\mathrm{N}(44)-\mathrm{H}(67)-\mathrm{O}(66), \mathrm{N}(73)$ $=\mathrm{H}(74) \cdots \mathrm{O}(13), \mathrm{N}(77)-\mathrm{H}(78)-\mathrm{O}(7), \mathrm{N}(10)-\cdots \mathrm{H}(44)-\mathrm{O}(43), \mathrm{N}(17)-\cdots \mathrm{H}(44)-\cdots$ $\mathrm{O}(43), \mathrm{N}(86)-\mathrm{H}(87)-\mathrm{O}(7)$ for $\mathrm{INH}[1-6]-\mathrm{TMH}$, respectively (see Table 1).

In this work, oxygen and nitrogen atoms as the electronegative atoms contribute the charge of electrons with hydrogen due to the formation of $\mathrm{H}$-bonding with the highest negative atomic charge on oxygen and nitrogen to the lowest negative atomic charge as $\mathrm{N}$-[[4-(4methylpiperazin-1-yl)phenyl]methyl]-1,2-oxazole-5-carboxamide $\quad(\mathrm{INH} 1)-\mathrm{TMH}>\quad[(\mathrm{Z})-1-$ thiophen-2-ylethylideneamino] thiourea (INH5-TMH)> (N-(2-aminoethyl)-1-1ziridineethanamine) (INH4)-TMH> NSC 158362 (INH2)-TMH> Vanillinbananin (INH6)-TMH> JMF 1586 (INH3)-TMH>, respectively (Figure 5).

In fact, the spin density and partial charges have been obtained by fitting the electrostatic potential to fix the charge of oxygen and nitrogen with high electronegativity in the junction of the electrophilic group of hydrogen in the structures of INH [1-6]-CoV as the anti-virus drugs which conduct us toward the industry of drug delivery. 


\section{Conclusions}

Generally, inhibitors are capable of joining the database amino acids fragment of Tyr160-Met161-His 162 as the selective zone of the coronavirus (CoV) by indicating the shift in their frequency and intensity spectra after estimation by the NMR method, which is affected by the atomic configuration of the inhibitors.

The stability of H-bonding between six inhibitors of N-[[4-(4-methylpiperazin-1yl)phenyl]methyl]-1,2-oxazole-5-carboxamide (INH1), NSC 158362 (INH2), JMF 1586 (INH3), (N-(2-aminoethyl)-1-1ziridine-ethanamine) (INH4), [(Z)-1-thiophen-2ylethylideneamino]thiourea (INH5) and Vanillinbananin (INH6) and coronavirus through the formation Inhibitor- $\mathrm{CoV}$ complexes through two probabilities of $\mathrm{N} \cdots \mathrm{H}$ and $\mathrm{O}=\mathrm{H}$ with different atomic charges has been investigated using IR methods. So, the thermodynamic properties of Gibbs free energy, enthalpy of formation, Electronic Energy, Core-Core interaction have approved the stability of anti-coronavirus complexes of INH [1-6]-TMH through the H-bonding formation using the drug delivery method.

\section{Funding}

This research received no external funding

\section{Acknowledgments}

This research has no acknowledgment.

\section{Conflicts of Interest}

The authors declare no conflict of interest.

\section{References}

1. Shereen, M.A.; Khan,S.; Kazmi, A.; Bashir, N.; Siddique, R. COVID-19 infection: Origin, transmission, and characteristics of human coronaviruses. J. Adv. Res. 2020, 2, 91-98, https://doi.org/10.1016/j.jare.2020.03.005.

2. Mishra, A.R.; Rani, P.; Krishankumar, R.; Ravichandran, K.S.; Kar, S. An extended fuzzy decision-making framework using hesitant fuzzy sets for the drug selection to treat the mild symptoms of coronavirus Disease 2019 (COVID-19). Appl Soft Comput 2021, 103, 107155, https://doi.org/10.1016/j.asoc.2021.107155.

3. Godoy, M.G.; Kibenge, M.J.T.; Kibenge, F.S.B. SARS-CoV-2 transmission via aquatic food animal species or their products: A review. Aquaculture 2021, 536, 736460, https://doi.org/10.1016/j.aquaculture.

4. Panwar, V.S.; Sheik Uduman, P.S.; Gómez-Aguilar, J.F. Mathematical modeling of coronavirus disease COVID-19 dynamics using CF and ABC non-singular fractional derivatives. Chaos Solitons Fractals 2021, 145, 110757, https://doi.org/10.1016/j.chaos.2021.110757.

5. Tuli, H.S.; Sood, S.; Kaur, J.; Kumar, P.; Seth, P.; Punia, S.; Yadav, P.; Sharma, A.K.; Aggarwal, D.; Sak, K. Mechanistic insight into anti-COVID-19 drugs: recent trends and advancements. 3 Biotech 2021, 11, 110, https://doi.org/10.1007/s13205-021-02644-8.

6. Hung, H.-M.; Yang, S.-L.; Chen, C.-J.; Chiu, C.-H.; Kuo, C.-Y.; Huang, K.-Y.A.; Lin, T.-Y.; Hsieh, Y.-C.; Gong, Y.-N.; Tsao, K.-C.; Huang, Y.-C. Molecular epidemiology and clinical features of rhinovirus infections among hospitalized patients in a medical center in Taiwan. J. Microbiol. Immunol. Infect. 2019, 52, 233-241, https://doi.org/10.1016/j.jmii.2018.08.009.

7. Chang, D.; Lin, M.; Wei, L.; Xie, L.; Zhu, G.; Dela Cruz, C.S.; Sharma, L. Epidemiologic and Clinical Characteristics of Novel Coronavirus Infections Involving 13 Patients Outside Wuhan, China. JAMA 2020, 323, 1092-1093, https://doi.org/10.1001/jama.2020.1623. 
8. Lai, C.C.; Shih, T.P; Ko, W.C.; Tang, H.Jen.; Hsueh, P.R. Severe acute respiratory syndrome coronavirus 2 (SARS-CoV-2) and coronavirus disease-2019 (COVID-19): The epidemic and the challenges. Int J Antimicrob Agents 2020, 55, 105924, https://doi.org/10.1016/j.ijantimicag.2020.105924.

9. Russell, C.D.; Millar, J.E.; Baillie, J.K.; Clinical evidence does not support corticosteroid treatment for 2019nCoV lung injury. Lancet 2020, 395:473-475, https://doi.org/10.1016/S0140-6736(20)30317-2.

10. Jiang, S.; Du, L. ; Shi, Z. An emerging coronavirus causing pneumonia outbreak in Wuhan, China: calling for developing therapeutic and prophylactic strategies. Emerg Microbes Infect 2020, 9, 275-277, https://doi.org/10.1080/22221751.2020.1723441.

11. Chen, N.; Zhou, M.; Dong, X.; Qu, J.; Gong, F.; Han, Y.; Qiu, Y.; Wang, J.; Liu, Y.; Wei, Y.; Xia, J.Epidemiological and clinical characteristics of 99 cases of 2019 novel coronavirus pneumonia in Wuhan, China: a descriptive study. The Lancet 2020, 395, 507-513, https://doi.org/10.1016/S0140-6736(20)30211-7.

12. Song,Z.; Xu,Y.; Bao,L.; Ling Zhang, L.; Yu,P.; Qu,Y.; Hua Zhu,H.; Zhao,W.; Han,Y.; Qin,C. From SARS to MERS, Thrusting Coronaviruses into the Spotlight. Viruses 2019, 11, 1-28, https://doi.org/10.3390/v11010059.

13. Tvarogová,J.; Madhugiri,R.; Bylapudi,G.; Ferguson, L.J.; Karl,N.; Ziebuhr,J. Identification and Characterization of a Human Coronavirus 229E Nonstructural Protein 8-Associated RNA 3'-Terminal Adenylyltransferase Activity. J. Virol 2019, 93, 1-21, https://doi.org/10.1128/JVI.00291-19.

14. Huang, C.; Wang, Y.; Li, X.; Ren, L.; Zhao, J.; Hu, Y.; Zhang, L.; Fan, G.; Xu, J.; Gu, X. Clinical features of patients infected with 2019 novel coronavirus in Wuhan, China. The lancet 2020, 395, 497-506, https://doi.org/10.1016/S0140-6736(20)30183-5.

15. Chan, J.F.-W.; Kok, K.-H.; Zhu, Z.; Chu, H.; To, K.K.-W.; Yuan, S.; Yuen, K.-Y. Genomic characterization of the 2019 novel human-pathogenic coronavirus isolated from a patient with atypical pneumonia after visiting Wuhan. Emerging Microbes \& Infections 2020, 9, 221-236, https://doi.org/10.1080/22221751.2020.1719902.

16. Ferron, F.; Subissi, L.; Silveira De Morais, A.T.; Le, N.T.T.; Sevajol, M.; Gluais, L.; Decroly, E.; Vonrhein, C; Bricogne, G.; Canard, B.; Imbert, I. Structural and molecular basis of mismatch correction and ribavirin excision from coronavirus RNA.Proc Natl Acad Sci USA 2018, 115, E162-E171, https://doi.org/10.1073/pnas.1718806115.

17. Yan, B.; Chu, H.; Yang, D.; Sze, K.-H.; Lai, P.-M.; Yuan, S.; Shuai, H.; Wang, Y.; Kao, R.Y.-T.; Chan, J.F.W.; Yuen, K.-Y. Characterization of the Lipidomic Profile of Human Coronavirus-Infected Cells: Implications for Lipid Metabolism Remodeling upon Coronavirus Replication. Viruses 2019, 11, 73, https://doi.org/10.3390/v11010073.

18. Monajjemi, M.; Noei, M.; Mollaamin, F. Design of fMet-tRNA and calculation of its bonding properties by quantum mechanics. Nucleosides, Nucleotides and Nucleic Acids 2010, 29, 9, https://doi.org/ 10.1080/15257771003781642.

19. Ksiaze k, T. G.; Erdman,D.; Goldsmith, C. S.; Zaki, S. R.; Peret,T.; Emery,S.; Tong,S.; Urbani,C.; Comer, J.A.; Lim, W.; Rollin, P.E.; Dowell, S.F.; Ling, A.E.; Humphrey, C.D.; Shieh, W.J.; Guarner,J.; Paddock,C.D.; Rota,P.; Fields,B.; DeRisi,J.; Yang, J.Y.; Cox,N.; Hughes, J.M.; LeDuc, J.W.; Bellini, W.J.; Anderson. L.J. A novel coronavirus associated with severe acute respiratory syndrome. N. Engl. J. Med 2003, 348, 1953-1966, https://doi.org/10.1056/NEJMoa030781.

20. Shi, C.-S.; Nabar, N.R.; Huang, N.-N.; Kehrl, J.H. SARS-Coronavirus Open Reading Frame-8b triggers intracellular stress pathways and activates NLRP3 inflammasomes. Cell Death Discovery 2019, 5, 101, https://doi.org/10.1038/s41420-019-0181-7.

21. Xia, S.; Yan, L.; Xu, W.; Agrawal, A.S.; Algaissi, A.; Tseng, C.-T.K.; Wang, Q.; Du, L.; Tan, W.; Wilson, I.A.; Jiang, S.; Yang, B.; Lu, L. A pan-coronavirus fusion inhibitor targeting the HR1 domain of human coronavirus spike. Science Advances 2019, 5, eaav4580, https://doi.org/10.1126/sciadv.aav4580.

22. Mitton, B.; Rule, R.; Said, M. Laboratory evaluation of the BioFire FilmArray Pneumonia plus panel compared to conventional methods for the identification of bacteria in lower respiratory tract specimens: a prospective cross-sectional study from South Africa. Diagn Microbiol Infect Dis 2021, 99, 115236, https://doi.org/10.1016/j.diagmicrobio.2020.115236.

23. Kao, C.-C.; Chiang, H.-T.; Chen, C.-Y.; Hung, C.-T.; Chen, Y.-C.; Su, L.-H.; Shi, Z.-Y.; Liu, J.-W.; Liu, C.P.; Chuang, Y.-C.; Ko, W.-C.; Chen, Y.-H.; Tseng, S.-H.; Lee, C.-M.; Lu, M.-C.; Hsueh, P.-R. National bundle care program implementation to reduce ventilator-associated pneumonia in intensive care units in Taiwan. J. Microbiol. Immunol. Infect. 2019, 52, 592-597, https://doi.org/10.1016/j.jmii.2017.11.001. 
24. Yen, M.Y.; Schwartz, J.; Chen, S.Y.; King, C.C.; Yang, G.Y.; Hsueh, P.R. Interrupting COVID-19 transmission by implementing enhanced traffic control bundling: Implications for global prevention and control efforts. J Microbiol Immunol Infect 2020, 53, 377-380, https://doi.org/10.1016/j.jmii.2020.03.011.

25. Álvarez-Lerma, F.; Sánchez García, M.; The multimodal approach for ventilator-associated pneumonia prevention"-requirements for nationwide implementation. Ann Transl Med 2018, 6, 420, https://doi.org/10.21037/atm.2018.08.40.

26. Caméléna, F.; Moy, A.-C.; Dudoignon, E.; Poncin, T.; Deniau, B.; Guillemet, L.; Le Goff, J.; Budoo, M.; Benyamina, M.; Chaussard, M.; Coutrot, M.; Lafaurie, M.; Plaud, B.; Mebazaa, A.; Depret, F.; Berçot, B. Performance of a multiplex polymerase chain reaction panel for identifying bacterial pathogens causing pneumonia in critically ill patients with COVID-19. Diagn. Microbiol. Infect. Dis. 2021, 99, 115183, https://doi.org/10.1016/j.diagmicrobio.2020.115183.

27. Dien Bard, J.; McElvania, E. Panels and Syndromic Testing in Clinical Microbiology. Clin Lab Med 2020, 40, 393-420, https://doi.org/10.1016/j.cll.2020.08.001.

28. Van, T.T.; Kim,T.H.; Butler-Wu, S.M. Evaluation of the Biofire FilmArray meningitis/encephalitis assay for the detection of Cryptococcus neoformans/gattii. Clin Microbiol Infect 2020, S1198-743X, 30031-30038, https://doi.org/10.1016/j.cmi.2020.01.007.

29. Tansarli, G.S.; Chapin, K.C. Diagnostic test accuracy of the BioFire(R) FilmArray(R) meningitis/encephalitis panel: a systematic review and meta-analysis. Clin Microbiol Infect 2020, 26, 281-290, https://doi.org/10.1016/j.cmi.2019.11.016.

30. Nabower, A.M.; Miller, S.; Biewen, B. Association of the FilmArray meningitis/encephalitis panel with clinical management. Hosp Pediatr. 2019, 9, 763-769, https://doi.org/10.1542/hpeds.2019-0064.

31. Cailleaux, M.; Pilmis, B.; Mizrahi, A.; Lourtet-Hascoet, J.; Van, J.-C.N.; Alix, L.; Couzigou, C.; Vidal, B.; Tattevin, P.; Le Monnier, A. Impact of a multiplex PCR assay (FilmArray®) on the management of patients with suspected central nervous system infections. Eur. J. Clin. Microbiol. Infect. Dis. 2020, 39, 293-297, https://doi.org/10.1007/s10096-019-03724-7.

32. She, R.C.; Bender, J.M. Advances in rapid molecular blood culture diagnostics: healthcare impact, laboratory implications, and multiplex technologies. J Appl Lab Med 2019, 3, 617-630, https://doi.org/10.1373/jalm.2018.027409.

33. Juttukonda, L.J.; Katz, S.; Gillon, J. Impact of a rapid blood culture diagnostic test in a children's hospital depends on Gram-positive versus Gram-negative organism and day versus night shift. J Clin Microbiol 2020, 58, e01400-e01419, https://doi.org/10.1128/JCM.01400-19.

34. Rand, K.H.; Beal, S.G.; Cherabuddi, K.; Couturier, B.; Lingenfelter, B.; Rindlisbacher, C.; Jones, J.; Houck H.J.; Lessard, K.J.; Tremblay, E.E. Performance of a Semiquantitative Multiplex Bacterial and Viral PCR Panel Compared With Standard Microbiological Laboratory Results: 396 Patients Studied With the BioFire Pneumonia Panel. Open Forum Infect Dis 2020, 8,ofaa560, https://doi.org/10.1093/ofid/ofaa560.

35. Blauwkamp, T.A.; Thair, S.; Rosen, M.J. Analytical and clinical validation of a microbial cell-free DNA sequencing test for infectious disease. Nat Microbiol 2019, 4, 663-674, https://doi.org/10.1038/s41564-0180349-6.

36. Hagen, A.; Eichinger, A.; Meyer-Buehn, M. Comparison of antibiotic and acyclovir usage before and after the implementation of an on-site FilmArray meningitis/encephalitis panel in an academic tertiary pediatric hospital: a retrospective observational study. BMC Pediatr 2020,20, 56, https://doi.org/10.1186/s12887-0201944-2.

37. Ryu, S.; Chun, B.C. Epidemiological characteristics of 2019 novel coronavirus: an interim review. Epidemiol Health 2020, 42, e2020006, https://doi.org/10.4178/epih.e2020006.

38. Lee, S.H.; Ruan, S.Y.; Pan, S.C.; Lee, T.F.; Chien, J.Y.; Hsueh P.R. Performance of a multiplex PCR pneumonia panel for the identification of respiratory pathogens and the main determinants of resistance from the lower respiratory tract specimens of adult patients in intensive care units. J Microbiol Immunol Infect 2019, 52, 920-928, https://doi.org/10.1016/j.jmii.2019.10.009.

39. Zhang, J.; Zhou, L.; Yang, Y.; Peng, W.; Wang, W.; Chen, X. Therapeutic and triage strategies for 2019 novel coronavirus disease in fever clinics. The Lancet Respiratory Medicine 2020, 8, e11-e12, https://doi.org/10.1016/S2213-2600(20)30071-0.

40. Pandey, U.; Greninger, A.L.; Levin, G.R. Pathogen or bystander: clinical significance of detecting human herpesvirus 6 in pediatric cerebrospinal fluid. JClin Microbiol 2020, 58, e00313-e00320, https://doi.org/10.1128/JCM.00313-20. 
41. Jiang, F.; Deng, L.; Zhang, L.; Cai, Y.; Cheung, C.W.; Xia, Z . Review of the Clinical Characteristics of Coronavirus Disease 2019 (COVID-19). J Gen Intern Med 2020, 35, 1545-1549, https://doi.org/10.1007/s11606-020-05762-w.

42. Frisch, M.J.; Trucks, G.W.; Schlegel, H.B.; Scuseria, G.E.; Robb, M.A.; Cheeseman, J.R.; Scalmani, G.; et al. Gaussian, Inc., Wallingford CT, 2009.

43. Mollaamin, F.; Monajjemi, M. Harmonic Linear Combination and Normal Mode Analysis of Semiconductor Nanotubes Vibrations. J. Comput. Theor. Nanosci 2015, 12, 1030-1039, https://doi.org/10.1166/jctn.2015.3846.

44. Roy, T. K.; Kopysov, V.; Pereverzev, A.; Šebek, J.; Gerber, R. B.; Boyarkin, O. V. Intrinsic structure of pentapeptide Leu-enkephalin geometry optimization and validation by comparison of VSCF-PT2 calculations with cold ion spectroscopy. Phys. Chem. Chem. Phys. 2018, 20, 24894-24901, https://doi.org/10.1039/c8cp03989e.

45. Ni, W.; Li, G.; Zhao, J.; Cui, J.; Wang, R.; Gao, Z.; Liu, Y. Use of Monte Carlo simulation to evaluate the efficacy of tigecycline and minocycline for the treatment of pneumonia due to carbapenemase-producing Klebsiella pneumoniae. Infect Dis (Lond) https://doi.org/10.1080/23744235.2018.1423703.

46. Kawczak, P.; Bober, L.; Bączek, T. QSAR analysis of selected antimicrobial structures belonging to nitroderivatives of heterocyclic compounds. Lett Drug Des Discov 2018c, 17, 214-225, https://doi.org/10.2174/1570180815666181004112947.

47. McArdle, S.; Mayorov, A.; Shan, X.; Benjamin, S.; Yuan, X. Digital quantum simulation of molecular vibrations. Chem. Sci. 2019, 10, 5725-5735, https://doi.org/10.1039/C9SC01313j.

48. Wang, S. Efficiently Calculating Anharmonic Frequencies of Molecular Vibration by Molecular Dynamics Trajectory Analysis. ACS Omega 2019, 4, 9271- 9283, https://doi.org/10.1021/acsomega.8b03364.

49. Monajjemi, M.; Mollaamin, F.; Gholami, M.R.; Yoosbashizadeh, H.; Sadrnezhad, S.K.; Passdar H.Quantum chemical parameters of some organic corrosion inhibitors, pyridine, 2-picoline 4-picoline and 2,4-lutidine, adsorption at aluminum surface in hydrocholoric and nitric acids and comparison between two acidic media. MAIN GROUP MET CHEM 2003, 26, 349-361, https://doi.org/10.1515/MGMC.2003.26.6.349.

50. Ghalandari, B.; Monajjemi, M.; Mollaamin, F. Theoretical Investigation of Carbon Nanotube Binding to DNA in View of Drug Delivery. J. Comput. Theor. Nanosci 2011, 8, 1212-1219, https://doi.org/10.1166/jctn.2011.1801.

51. Cohen, G.; Eisenberg, H. Deoxyribonucleate solutions: sedimentation in a density gradient, partial specific volumes, density and refractive index increments, and preferential interactions. Biopolymers 1968, 6, 1077 1100, https://doi.org/10.1002/bip.1968.360060805.

52. Beak, P.; Covington, J.B.; Smith, S.G.; White, J.M.; Zeiger, J.M. Displacement of protomeric equilibriums by self-association: hydroxypyridine-pyridone and mercaptopyridine-thiopyridone isomer pairs. J. Org. Chem 1980, 45,1354-1362, https://doi.org/10.1021/jo01296a002.

53. Sarasia, E.M.; Afsharnezhad, S.; Honarparvar, B.; Mollaamin, F.; Monajjemi, M. Theoretical study of solvent effect on NMR shielding tensors of luciferin derivatives. Phys. Chem. Liq. 2011, 49, 561-571, https://doi.org/10.1080/00319101003698992.

54. Monajjemi, M.; Mahdavian, L.; Mollaamin, F.; Khaleghian, M. Interaction of Na, Mg, Al, Si with carbon nanotube (CNT): NMR and IR study. Russ. J. Inorg. Chem 2009, 54, 1465-1473, https://doi.org/10.1134/S0036023609090216.

55. Polzella, M.S.; Lodeyro, P. Re-evaluating semi-empirical computer simulations in quantum chemistry. Found Chem 2019, 21, 83-95, https://doi.org/10.1007/s10698-018-09329-w.

56. Kirkwood, J.G. On the Theory of Strong Electrolyte Solutions, J. Chem. Phys 1934, 2, 767, https://doi.org/10.1063/1.1749393. 
57. Kirkwood, J.G. The Dielectric Polarization of Polar Liquids. J. Chem. Phys 1939, 7, 911, https://doi.org/10.1063/1.1750343.

58. Onsager, L. Electric Moments of Molecules in Liquids. J. Am. Chem. Soc 1936, 58, 1486-1493, https://doi.org/10.1021/ja01299a050.

59. Khaleghian, M.; Zahmatkesh, M.; Mollaamin, F.; Monajjemi, M. Investigation of solvent effects on armchair single-walled carbon nanotubes: A QM/MD study. Fullerenes Nanotubes and Carbon Nanostructures 2011, 19, 4, https://doi.org/10.1080/15363831003721757.

60. Monajjemi, M.; Afsharnezhad, S.; Jaafari, M.R.; Mirdamadi, S.; Mollaamin, F.; Monajemi, H. Investigation of energy and NMR isotropic shift on the internal rotation Barrier of $\Theta 4$ dihedral angle of the DLPC: A GIAO study. Chemistry 2008, 17, 1.

61. Lee, V.S.; Nimmanpipug, P.; Mollaamin, F.; Kungwan, N.; Thanasanvorakun, S.; Monajjemi, M. Investigation of single wall carbon nanotubes electrical properties and normal mode analysis: Dielectric effects. Russ. J. Phys. Chem A 2009, 83, 2288-2296, https://doi.org/10.1134/S0036024409130184.

62. Monajjemi, M.; Farahani, N.; Mollaamin, F. Thermodynamic study of solvent effects on nanostructures: Phosphatidylserine and phosphatidylinositol membranes. Phys. Chem. Liq 2012, 50, 161-172, https://doi.org/10.1080/00319104.2010.527842. 